\title{
Conceptual and procedural approaches to mathematics in the engineering curriculum: Views of qualified engineers
}

J ohann Engelbrecht, Christer Bergsten and Owe Kågesten

The self-archived version of this journal article is available at Linköping University Electronic Press:

http:/ / urn.kb.se/ resolve?urn=urn:nbn:se:liu:diva- 139232

N.B.: When citing this work, cite the original publication.

This is an electronic version of an article published in:

Engelbrecht, J., Bergsten, C., Kågesten, O., (2017), Conceptual and procedural approaches to mathematics in the engineering curriculum: Views of qualified engineers, European J ournal of Engineering Education. https:// dx.doi.org/ 10.1080/ 03043797.2017.1343278

Original publication available at:

https:/ / dx.doi.org/ 10.1080/ 03043797.2017.1343278

Copyright: Taylor \& Francis: STM, Behavioural Science and Public Health Titles http:// www.tandf.co.uk/journals/ default.asp 


\title{
Conceptual and Procedural Approaches to Mathematics in the Engineering Curriculum: Views of Qualified Engineers
}

\author{
Johann Engelbrecht*, Christer Bergsten**, Owe Kågesten** \\ * University of Pretoria, South Africa, ** Linköping University, Sweden
}

\begin{abstract}
The research interest underpinning this paper concerns the type of mathematical knowledge engineering students may acquire during their specialised education in terms of the conceptual and procedural dimensions of doing and using mathematics. This study draws on interviews with 25 qualified engineers from South Africa and Sweden regarding their views on the role of mathematics in engineering education, with special focus on the conceptual and procedural aspects of mathematical knowledge. A thematic analysis of the interview data led to the identification of two main themes. According to the conceptual view a predominantly conceptual approach is needed and valued more than procedural skills, while the balanced view emphasises a balance of conceptual understanding and procedural fluency as well as links between them. It is suggested that the mathematical education of engineers would need to be more conceptually oriented to prepare for the demands at the workplace.
\end{abstract}

Keywords: conceptual and procedural knowledge; undergraduate mathematics; engineering education; views of engineers

\section{Introduction}

Due to the multifaceted character of the engineering profession, the education of engineers generally offers a range of study directions and specialisations. However, the organisation of the education commonly includes one or two introductory years of 'basic courses', including mathematics and physics. However, as the general aim of these courses is to serve as a knowledge base for later more 'applied' engineering subjects, students may experience them as only weakly related to their future work as engineers. While engineering education had been based on the practice of engineering up to "the advent of the modern engineering science based approach to engineering education in the 1950's", more recently the "widening gulf between engineering education and practice" has begun to be addressed (Crawley 2001, 1-2). Apart from problems to provide an adequate (mathematical) preparation for their future work as engineers, such distance to "real engineering problems" in their education also has a negative effect on students' motivation (Perdigones et al. 2014, 1509). It may also have led to an observed "expectation gap” between employers of engineers and graduates (Wood 2010, 189).

There is still, however, little consensus among educators on what type of mathematical knowledge an engineer should acquire during the education, in particular when considering the role of computing technologies in professional contexts. Flegg, Mallet and Lupton (2012, 718) write, based on a range of studies, that "there seems to be no consistent, researchinformed, view of how, what, when and by whom mathematics should be taught to engineering students", and while the mathematical education during the engineering studies is seen as crucial for engineering competency (Kent and Noss 2003), the kind of mathematical knowledge employers expect differs (Nguyen 1998). 
In early studies on the role of mathematics in engineering education, the focus was largely on the selection of mathematical topics to teach. For example, when Håstad (1968) investigated what mathematics different types of engineers actually use in their professional activity, the participants in the study were asked to respond to a list of mathematical “disciplines". Much later, the curriculum framework document developed by the European Society for Engineering Education (SEFI) Mathematics Working Group in 1992, was still strongly topic oriented (Alpers 2013a). However, an interest soon developed not only in what to study but also on how to study mathematics and what kind of mathematical knowledge is needed in engineering work. While demands from engineering faculties often have emphasised computational mathematical skills more than understanding of mathematical ideas and concepts, at the same time, analytic and creative knowledge based skills are expected from engineers in the workplace (Chundi 2013). This would point to a need of conceptual mathematical knowledge along with generic skills such as analytical thinking and problem solving (Alpers 2013b; Crawley 2001). Considering the development and availability of advanced computational tools, such as computer algebra systems, an approach in teaching mathematics to engineers with emphasis on the development of procedural skills may currently appear less important for the mathematical education of engineers (cf. Kent and Noss 2003).

To this background, the study reported here takes its focus on the type of mathematical knowledge engineering students may acquire during their specialised education in terms of the conceptual and procedural dimensions of doing and using mathematics in engineering. Considering the tension between mathematics teaching at the undergraduate level and the development of computing technology, the main objective with the overarching project for this study has been to investigate the current needs that engineering students and engineers have of mathematics regarding its conceptual and procedural aspects. While previous studies within the project explored this issue from the students' perspective (Engelbrecht, Bergsten, and Kågesten 2009, 2012; Bergsten, Engelbrecht, and Kågesten 2017), the present study is based on interviews with 25 professional engineers and university lecturers of engineering subjects regarding their views on the role of mathematics in engineering education, with special focus on the issue of the conceptual and procedural aspects of mathematical knowledge. While Bergsten, Engelbrecht and Kågesten (2015) presented a detailed case study report on two of these interviews, this paper presents and discusses the findings from the full interview study.

\section{Mathematics for Engineering Education}

To investigate the mathematical needs for future engineers, research has explored the use of mathematics at workplaces as well as students' and university teachers' views on the mathematical training in engineering education. Questions of interest have concerned, for example, the types of mathematical knowledge engineers need, the characterisation of a 'minimum level' of mathematical knowledge still essential to the practice of engineering, changes of practice and education prompted by computer technology, and how and when mathematics should be taught (Kent and Noss 2003). Kent and Noss claim that mathematics "is and will remain crucial” for engineering education (8). Similarly, in an Australian survey with qualified engineers, Henderson and Broadbridge (2009) found that most professional and academic engineers agree that engineers need a "good grounding in mathematics, including general logic and problem solving” (15). However, the authors expressed concern about a lack of confidence in using mathematics among many professional engineers. In a review of studies on engineering workplace mathematics, Alpers (2010) identified a range of critical categories that "capture the way mathematical thinking or activities occur during the work on practical problems” (3). These categories include, among others, contextual 
embedding of mathematical models, as well as concepts and procedures; the need to reflect on concepts and model assumptions in non-standard situations; a recognition that the operation of technological tools requires understanding of mathematical notations and graphics; and an appreciation that while mathematics is important for engineering design this relies on engineering judgment and sceptical reverence. The latter notion involves seeing mathematics as "a powerful and necessary tool for engineering that must be used judiciously and sceptically” (Gainsburg 2015, 143). Based on observations and interviews of junior and senior engineering students as well as practising engineers engaged in project work, Cardella (2008) suggests a similar wide approach to the mathematical needs of engineers. This is in line with what Kent and Noss (2003) call an holistic awareness of the mathematical needs for engineering work, which was seen as more important than manipulative skills by the practising engineers and mathematicians interviewed in their study. The study also pointed to a need to communicate mathematical ideas in engineering work, an issue emphasised by Vest, Long, and Anderson (1996) as important to include in the engineering curriculum. More recently, Goold (2014) found strong support in research literature for the importance of communication of mathematical ideas in the mathematical training of engineering students. This may be seen in the light of "global competencies" (e.g., Nair et al. 2009, 133) requirements meeting the modern engineer in a changing society, where general communicational abilities have become more important (Grimson 2002; Lappalainen 2009).

At such more general level, Nguyen (1998) conducted a survey administered to academics, industry personnel and students in Australia with the objective of eliciting their views on what generic and specialist skills and attributes are essential for a modern engineer. Her results point to the importance of technical knowledge and skills, including problem solving and logical skills and knowledge about "how to behave and operate within an organisation" (73). Specific mathematical skills were not emphasised in the survey. Similarly, in a literature review on "employability skill needs in engineering” (Markes 2006), the word 'mathematics' occurs only once. In this context, Wood (2010) points out that there is "a significant expectation gap between employers and graduates" (189) and that students' adjustment to engineering work becomes problematic when what they learn "needs to be applied in a different context” (190).

Students' experiences of their mathematical education have been highlighted in a series of comprehensive international studies by Houston et al. (2010), Petocz et al. (2007), and Wood et al. (2012), which revealed that undergraduates hold a range of ideas and positions relative to the 'transitions' within education and beyond. Some students in these studies were unsure about how the mathematics they were studying would be used or its role for their careers. For the present study, it is interesting to note the concern raised by Wood et al. (2012) that there was a "relatively low number of students who saw the application of conceptual skills as an important way in which mathematics could affect their future studies (6.9\%) and career (5.8\%)” (116). Here Gainsburg (2015) suggests that the epistemic frame surrounding engineering education subjects, especially mathematics, does not promote an open and critical attitude to the use of mathematics in engineering work. That the mathematical education of engineers does not always connect well with their future professional practice was also pointed out in a European context by Hult et al. (2003), affecting engineering students' future professional identity. Regarding the transition from the training at university to professional work, Wood and Solomonides (2008) argue that it is possible, by the incorporation of different approaches into learning substantial university mathematics while keeping the "real graduate capabilities/attributes" in focus, to support the development of a future professional identity. 
The literature reviewed thus points to the need to view the mathematical education of engineers in a wider perspective beyond mathematical content issues, including also its conceptual and procedural aspects while considering the context of engineering work.

\section{Conceptual and procedural Approaches to Mathematics}

At many institutes of engineering education, introductory mathematics courses are often taught at mathematics departments where the subject is treated as valuable knowledge in its own right, with its own knowledge criteria, more than as a service subject for practical use outside mathematics. There is also a strong tradition regarding the content of these courses as well as teaching approaches (Klingbeil et al. 2005). However, within this 'traditional' undergraduate mathematics teaching there is a difference between taking a predominantly conceptual or procedural approach. Teaching with a focus on fostering conceptual understanding might draw on a contextualised problem asking students "to uncover patterns and relationships”, thus providing a contextual basis for the new mathematical knowledge requiring students to connect to their prior knowledge (Brown, Seidelmann and Zimmermann 2006, n.p., see also Star 2005). Taking an approach which is more procedurally oriented, the lecturer may instead begin with a presentation of definitions, notations and procedures without first providing meaningful contexts for the concepts involved (Brown, Seidelmann and Zimmermann 2006; Wu 1999). ${ }^{1}$ When mathematics is studied mainly to serve as a foundation and pre-requisite for other subjects, it may lead to more emphasis on procedural fluency than on conceptual understanding (Winkelman 2009).

Within mathematics education, Hiebert and Lefevre (1986) define conceptual knowledge as a connected network of knowledge in which "the linking relationships are as prominent as the discrete pieces of information" (3-4), while procedural knowledge is described in terms of both, the step-by-step procedures for the solution of mathematical tasks and the symbolic representations used in such procedures ${ }^{2}$. Competency in mathematics comprises, in this perspective, knowledge of concepts and procedures along with relations between these two types of knowledge (Hiebert and Carpenter 1992). However, potential links between conceptual and procedural knowledge have been characterised by their complexity (Peled and Zaslavski 2008; Rittle-Johnson and Schneider 2015). While procedural knowledge may underpin conceptual knowledge, conceptual knowledge may influence or even become procedural knowledge with repeated exposure (Artigue 2007; Rittle-Johnson, Siegler and Alibali 2001), and while some authors see them as independent (e.g. Radu 2002), others have emphasised a dynamic and evolutionary relationship (e.g. Baroody, Feil, and Johnson 2007; Rittle-Johnson and Schneider 2015; Star 2005). Kieran (2013), however, calls the distinction between conceptual and procedural knowledge a false dichotomy, and $\mathrm{Wu}$, in the context of more advanced mathematics, argues from a number of examples that "in mathematics, skills and understanding are completely intertwined” and calls it a bogus dichotomy (Wu 1999, 2).

While considering these different research claims, it is necessary to keep in mind that they may relate to different interpretations of the terms conceptual and procedural knowledge. For example, Rittle-Johnson, Siegler and Alibali (2001) define conceptual knowledge as "implicit or explicit understanding of the principles that govern a domain and of the interrelations between units of knowledge in a domain", while procedural knowledge is "the ability to execute action sequences to solve problems" (346). In contrast to procedural knowledge, conceptual knowledge "is flexible and not tied to specific problem types and is therefore

\footnotetext{
${ }^{1}$ For an example of a teaching experiment in undergraduate mathematics based on these constructs, see Chappell and Killpatrick (2003).

2 These two aspects of procedural knowledge have been called algorithmic and syntactic knowledge, respectively (Groth and Bergner 2006, 40).
} 
generalizable” (347). Rittle-Johnson and Schneider (2015) contend that in more recent research, the term conceptual knowledge refers more generally to knowledge of concepts while it "views the richness of connections as a feature of conceptual knowledge that increases with expertise" (1119).

In the context of mathematics in engineering education, the relation between conceptual and procedural approaches to solving mathematics tasks has been investigated within the larger project for the present study. Engelbrecht, Bergsten and Kågesten (2009) found that first year students tended to 'proceduralise' tasks that had a more conceptual focus, which sometimes required "quite sophisticated mathematical work" (939), thus indicating the viability of exploiting the relationship between conceptual and procedural knowledge. A follow-up study by Engelbrecht, Bergsten and Kågesten (2012) investigated junior engineering students' achievement and views on conceptually versus procedurally focused mathematical tasks. The study showed that the students considered procedural questions as more common in their mathematics curriculum, while conceptual (mathematical) questions were seen as more common in the engineering subjects. They also expressed a higher confidence in their performance on the procedural tasks. However, both types of tasks were seen as relevant for their engineering studies. In Bergsten, Engelbrecht and Kågesten (2017) strong correlations between performance and confidence for the procedural items for both junior and senior students were found, while for the conceptual items these correlations were much stronger for the senior than for the junior students. This points to an increased familiarity with the conceptual aspects of mathematics through its use in applied subjects throughout the education.

\section{Focus and Design of the Research}

This paper reports from a collaboration project between two universities, one in South Africa and one in Sweden. In this project we have sourced information to compare three target groups in the two countries - engineering students, lecturers and practising engineers regarding their views on the role of mathematics in engineering education, in particular regarding conceptual/procedural approaches as discussed above. While differences in culture and organization between the countries/institutions may provide insights about each local situation, similarities and differences may also be discerned which might provide a theoretical basis as well as practical suggestions for how to organise the education. In addition to pragmatic reasons being one basis for the selection of the particular institutions, both are comprehensive high ranked universities in their respective countries and have strong engineering faculties that have been running engineering education for many years.

Based on the research based discussion above, for our studies within this project we are using the following working definitions of conceptual/procedural approaches in the mathematical education of engineers:

- A conceptual approach includes translations between verbal, visual (graphical), numerical and formal/algebraic mathematical expressions (representations); linking relationships; and interpretations and applications of concepts (for example by way of diagrams) to mathematical situations.

- A procedural approach includes (algebraic and numerical) calculations, employing (given) rules, algorithms, formulae and symbols.

For the part of the study reported in this paper, addressing practicing engineers, we set up the following research question:

- How do professional engineers view the relevance and role of conceptual and procedural mathematical skills in the education and practices of engineers? 


\subsection{Participants and Interviews}

To investigate the research question we conducted individual interviews with a total of 25 qualified and experienced engineers who all did their initial training as engineers at academic universities, representing a wide range of engineering areas. They were selected through purposive sampling, which "entails an attempt to establish a good correspondence between research questions and sampling” (Bryman 2004, 333), combining a convenience and a snowball approach (100). We included three different groups of engineers to include views from a broad spectrum of role players:

- 9 qualified engineers who are practising as actual engineers (referred to as $P E$ further on in this paper) - 3 from South Africa and 6 from Sweden.

- 5 qualified engineers in managerial positions (referred to as $M E$ further on) - 2 from South Africa and 3 from Sweden.

- 11 university lecturers in applied (engineering) subjects (referred to as UL further on) - 6 from South Africa and 5 from Sweden.

By investigating a variety of exemplifying cases (Bryman 2004, 51), we hoped to be able to find different kinds of arguments regarding the role of mathematics in engineering work, as well as some that were common across the contexts.

All interviews were audio recorded and transcribed. Interviews with South African engineers were conducted in English by one of the researchers and in some cases by a masters student. In Sweden the interviews were conducted in Swedish by one of the researchers; the interview protocols were then translated into English.

The interviews were semi-structured (Bryman 2004, 321). The concepts of conceptual and procedural approaches were initially highlighted to the interviewee, using our working definitions and a few examples of (basic mathematics) items from the research instrument used with the students (see Engelbrecht, Bergsten, and Kågesten 2012); these items were discussed (without expecting them to actually answer them) and then the interviewee's opinion on the issue was sourced based on guiding questions (see below). Interviewees were informed and agreed to the fact that findings from the interview study would be published in research journals, including excerpts from the interview protocol, while keeping full anonymity of the participants.

To investigate the research question, for the groups of practising and managing engineers the interviews were organised by the following guiding questions:

1. From the point of view of your present professional activities, what is your opinion on your own mathematical schooling from your engineering education?

2. If you were involved in training engineers, which approach would you use?

3. Which approach is more relevant for the work you do (procedural or conceptual)?

4. Should engineers that you would employ have conceptual or procedural skills?

In the interviews with the university lecturers in applied engineering subjects we used the following guiding questions:

A. Do students coming into your courses have the required procedural and conceptual skills?

B. Which approach is more relevant for courses you teach?

C. Which approach is the most relevant/important for engineering students to become an engineer?

D. Should engineering students have conceptual or procedural skills? 


\subsection{Analysis}

For the purpose of our study we found a thematic analysis adequate for our explorative investigation. According to Braun and Clarke (2006) a thematic analysis, being primarily "a method for identifying, analysing and reporting patterns (themes) within data” (78), does not assume neither, a realist/essentialist or constructionist approach, giving it both theoretical freedom and flexibility. Following their terminology (79), our data set consists of the (transcribed) interviews we conducted with three different groups of qualified engineers, and our data items are the individual interviews. The data extracts are those parts of the data items that have been coded during the analysis and of which a subset contribute to the final analysis. While we assume that what the interviewees communicate during the interviews reflect their experiences and opinions on the issues discussed, we also acknowledge that our formulations of the key notions and questions, as well as the interview settings themselves, are constituent element of the discourse that developed during the interviews. As we did not aim to consider overall contexts and social relationships that might explain the opinions put forward by the participants (latent themes), we conducted a semantic analysis reflecting the opinions put forward by the individual engineers, thus aiming to identify semantic themes that reflect the main patterns we found in our data (Braun and Clarke 2006, p. 86).

All interview transcripts were analysed by the researchers in collaboration. For the analysis the answers to guiding questions 2 and $\mathrm{B}$ were grouped together, as they referred to the same issue from the different professional perspectives of the interviewees. The same procedure was used for questions 3 and $\mathrm{C}$ and for questions 4 and D. Questions 1 and A are related as they both address prerequisite knowledge but for different things; they were analysed separately. The analysis was organised, country by country, by way of a matrix where answers from each interviewee, grouped by the three categories of qualified engineers that participated, were inserted in columns sorted by questions. By identifying semantic categories of responses (using coloured codes) in a column across interviewees, main themes of standpoints and arguments for each question could be identified, with some subthemes. These themes and subthemes are shown in Table 1 together with examples of codes used for their identification.

The matrix organisation (with the coloured codes) also made it possible to describe similarities and differences between the views of the engineers for each question. A characterization of the overall view of each interviewee on the procedural/conceptual issue was obtained by focusing on the rows of the matrix. This analysis showed a high level of theme consistency within the answers of an interviewee across questions, an observation which led to a second analysis of the themes (and their interrelations) from the perspective of the overall research question/interest. This second analysis, and a review of the material, led to the identification of two final main themes and linked subthemes, drawing on the principle that data within the themes should "cohere together meaningfully, while there should be clear and identifiable distinctions between themes” (Braun and Clarke 2006, p. 91). This final thematic map (89-91) is presented in Figure 1. The organisation of the interview transcript also allowed an analysis at engineering group level. Finally, keeping each matrix as a whole in focus, the views of the engineers from the two countries could be compared.

\section{Findings}

For the first step of the thematic analysis, the presentation of the data is organised under headings with reference to the guiding questions above (Q1, 2, 3, 4, and QA, B, C, D). The interviewees will be referred to as ME1, PE2 and UL3, for example, where the letters indicate the group of engineers they belong to (ME, PE or UL) and the number the identification given within their group. As only small differences in views expressed by the 
engineers in the two countries and in the three groups were identified, the presentation of the interview data will not be separated between countries or groups; differences that were identified in the analysis will be commented on in the data presentation as well as in the discussion.

For the reader to get a sense of the lines of argument that were expressed by the interviewees, the data presentation will include several excerpts from the interview transcripts rather than snapshots followed by attempts of concise reformulations. This way also themes and corresponding codes that we defined in our analysis (see Table 1) may become transparent.

\subsection{Own Mathematical Schooling (Q1)}

The interviewees were generally pleased with what they have got out of their own mathematical studies, arguing that these were adequate and useful for their current professional work.

It was quite right for me - it had just enough depth. [...] It might be somewhat away from reality, at least my reality, but it's been quite right for the job I have now. (ME4 - Sweden)

The mathematics that I had done at university had adequately prepared me for what I needed to do in my professional capacity. I didn't feel there was anything lacking in either my conceptual or procedural abilities. Both were adequate. (PE3 - SA)

Some engineers, however, expressed the opinion that the mathematics they were taught at university was mainly procedural and pointed to a lack of applications to reality (as was also indicated by ME4 above).

The maths was very procedural. And the work we do now is very conceptual. (PE1 - SA)

A little problematic to connect mathematics to the physical reality, that was the big thing really [...] you have to specify the tasks and why it needs to be calculated. (PE8 - Sweden)

According to a few of the interviewees the mathematics they studied was not much used in their work but it is important to have it as a basis for understanding engineering issues.

We use very little of it, especially with the software that you've got now. (PE1 - SA)

I am more a practitioner than a theorist, so I consider mathematics more as a means to understand. (PE5 Sweden)

Although some engineers described their own mathematical training at university as too much procedural and disconnected to reality, the dominating impression is one of satisfaction with the mathematical background from their education - they expressed that they have control of what they can do mathematically and can develop an intuitive understanding of concepts relevant to their work.

\subsection{Preparedness: Do Students Coming into your Courses have the Required Procedural and Conceptual Skills? (QA)}

Many lecturers in both countries complained about the level of conceptual understanding exposed by students in later years of their studies - after they have gone through the formal mathematics courses. Rather, they look for standard examples to be able to apply known procedures. This was by some lecturers linked to problems to communicate mathematical thinking.

It would be enormously beneficial if the students had some conceptual background coming into our courses. Their conceptual abilities are very poorly developed. (UL6 - SA)

Students find it difficult to express themselves mathematically. They would look for a standard example, you solve it in this way, using this and these formulas or algorithms. (UL10- Sweden) 
So I find that I have to almost unteach a little bit of the very heavy procedural mathematics, so that they are able to look at a complex engineering problem and let the problems speak to them and they speak and communicate their thinking with a problem to be able to solve it. (UL4 - SA)

The issue of communication, seen as essential for complex problem solving, was not seen to be promoted by a strong procedural approach (UL4). While discussing this question, though, some interviewees emphasised the need also for procedural mathematics and to be able to link between conceptual and procedural situations.

It's important that they have both these types of skills, so that even if they understand, they have to be able to do the craftwork; for the engineering programme that I am [teaching] now, the conceptual is most important. (UL7 - Sweden)

So procedurally I think they are well equipped. They do not have adequate conceptual skills and that ability to link between conceptual and procedural. But I will admit that I did not have it either. (UL2 - SA)

Interviewees strongly recommended that the context of a particular procedural problem should be explained to students to make them aware of where in industry the problem would be needed. It was also pointed out that many conceptual issues are raised outside the mathematics courses.

That is one feedback we get from students - they are just taught a lot of maths. They don't understand why they need it ... I would prefer them to have less maths knowledge but more in-depth, really understand what you are doing. (UL1 - SA)

But then most of the conceptual understanding is taught in non-mathematics subjects because we use so much of the basic sciences - maths, physics and chemistry. (UL5 - SA)

In summary, when discussing the issue of preparedness, several engineers added pedagogical suggestions. They pointed to a lack of conceptual skills as well as of not being able to connect the procedural to the conceptual. An ability to communicate such type of knowledge was described as valuable, as well as providing connections to real applications.

\subsection{Relevance for Engineering Courses - which Approach should be Used in Training Engineering Students? (Q2B)}

Most of the interviewees put forward the opinion that in the mathematical education of engineers, a stronger focus should be placed on conceptual aspects. The arguments were often linked to specific topics.

The concept is always the most important thing when it comes to applied topics, to understand why we use this differential equation, where does the differential equation come from and the integral equations, and also what happens if you make a change to the system. (PE8 - Sweden)

Ultimately conceptual understanding should arrive. If that could be accomplished by teaching procedurally then I would be happy but the real objective is for conceptual understanding to arrive. (UL3 - RSA)

However, a balance between the two aspects was also emphasised - even more so by Swedish engineers.

I would probably try to keep some sort of balance there, maybe a slight shift toward those conceptual elements but I don't want to sacrifice too much of the purely computational. (PE4 - Sweden)

It's important that they have both these types of skills, so although they understand they still need to do the craftwork ... a conceptually well-established approach from the student often results in a good technical application (UL7 - Sweden)

In this context, a view put forward by several engineers from both countries, was that procedural training should precede conceptual applications, often with the argument to provide a "base" for the understanding of the latter.

You have to have the computational basis for building the conceptual. (ME6 - Sweden) 
I would be looking at using the first year procedural mathematics as a base and then move on to the conceptual approach. But then we also want them to be able to create their own procedures. (UL4 - SA)

You can’t be simply a, a thinker ... In the beginning you need to get this schooling and learn the language, then maybe later, you move more and more into the problem. (ME3 - Sweden)

However, switching the order by first forming a conceptual basis and then move to a procedural solution was also mentioned and supported by a number of interviewees ${ }^{3}$.

Conceptual understanding is needed to set up a problem and procedural knowledge needed to solve it.

To get them to understand a problem first, before looking whether a formula is necessary instead of what formula is necessary is quite an exercise. (UL6 - SA)

It should be more on the conceptual but you might, to some extent, have a minimum of computations too. In the end you want to think like engineers especially when developing new models or new ways of tackling problems. You first have a concrete description of a problem and then go to a mathematical formulation. (UL11- Sweden)

The dynamics between conceptual and procedural thinking was also debated. It was pointed out that repeated exposure to concepts leads to start handling them as procedures, not having to consider the meaning of them all over again.

I think the trick is always to reduce the conceptual to the procedural (PE2 - SA).

It was also suggested that mathematics provides a pathway to how to think.

To me, our students' mathematical knowledge does not have to be at a very high level but they need to understand how to use their brains and think originally - to me the concept of how you need to think is what we want from mathematics. (UL1 - SA)

There was general consensus that ultimately conceptual understanding should arrive and the majority of the interviewees suggested a more conceptually focused undergraduate teaching. There was some difference in opinion, though, on whether the conceptual skills should be accomplished by starting with a procedural approach before moving to the applications, or whether one should start with the conceptual problem and then decide what procedures are needed for its solution. Swedish engineers, in particular, emphasised a balance between a conceptual and procedural approach.

\subsection{Relevance for the Engineering Work (Q3C)}

Engineers generally expressed the opinion that conceptual mathematics is more important in order to become a successful engineer. The emphasis on (only) the conceptual was stronger among the South African than with the Swedish engineers.

I think that the students need the same conceptual skills to firstly qualify as a professional engineer and then to be successful in the work place. (UL1 - SA)

Definitely the conceptual. Procedural is easy and you can outsource that, but the conceptual is really the challenge for me. (PE2 - SA)

I think the conceptual is more important just because an engineer is supposed to develop new technology. (UL9 - Sweden)

The concept is always the most important as the basis. (PE8 - Sweden)

Linking the conceptual to real engineering problems was seen as essential.

In the real world, it is not pure academic situations that you face, it is real world problems, so definitely the conceptual. (ME1 - SA)

\footnotetext{
${ }^{3}$ This approach has been used in the CDIO (Conceive, Design, Implement, Operate) approach to engineering education, followed at MIT (Crawley 2001).
} 
If you really want to look at changing the curriculum, going more conceptual but also then linking it to Engineering. (UL1 - SA)

Some engineers claimed that both (conceptual and procedural) are needed, but that it is the conceptual that is the basis for assumptions and design. An essential issue that was pointed at is the ability to link the conceptual engineering problem to a procedural mathematical problem.

Both, and since I do computational methods, I must first have an idea of how to translate what you want to calculate to a language which can be implemented on a computer and that phase encompasses the conceptual. (PE4 - Sweden)

Professional engineers are bombarded more with the conceptual side, but because they can't make the link between conceptual and procedural approach, they end up solving it heuristically. They don't have an appreciation for the procedural side and the problem is linking the conceptual to the procedural. (UL2 - SA)

That procedural thinking is needed was emphasised by some engineers, in particular as a basis for developing conceptual understanding. However, the computational part was considered as a lower level activity by some engineers.

I think you do need some procedure background, some procedural knowledge. The question in my mind is how much, what is the proportion? So I would be looking for a procedural base and building a conceptual understanding onto that. (UL6 - SA)

The computational is a little like doing it with the spine, while the conceptual involves a little more thinking and also the feature that I think is important - to evaluate the results. (PE7 - Sweden)

The engineers thus expressed the overall opinion (South African engineers even more so) that a conceptual approach to mathematics is more relevant in the engineering profession. Some engineers (mainly Swedish) still pointed to a need for procedures and were in favour of a balance between the approaches.

\subsection{Employability (Q4D)}

According to several interviewees, companies prefer young qualified engineers with conceptual skills.

I will say conceptual is definitely what we need, because that is what the industry actually needs. We are looking for people who can think and solve the problems and find where the mathematics fit into solving the problem at hand. (PE1 - SA)

I think if we overproceduralise we could run into problems because we'll have a shortage of the more open minded problem solving type of engineers. (UL5 - SA)

One argument for the preference of conceptually oriented engineers referred to them as having a higher level competence.

If one is conceptual then you stand a notch above someone who just can deal with computational math. If you know the conceptual, you can switch over to the computational, while it is difficult for those who have just reached the computational level to get to the conceptual level. (PE7 - Sweden)

The thing with procedures is, if you forget them, you can always go and restudy them. Whereas if you don't have the conceptual understanding, it is quite hard to learn. It is something that needs to be developed. (PE3 - SA)

Many of the South African engineers found the conceptual knowledge of new graduates too low for the job market.

I do not feel that the students who graduate from the University have the required conceptual skills to be successful in the workplace. (UL6 - SA)

Some engineers, the Swedish ones more often so, pointed to the need of having both procedural and conceptual knowledge, also depending on the kind of job to be done. 
Both [conceptual and procedural skills] must be there. If you only have one of those two, it feels like it is limping; you need both. (PE9 - Sweden)

Without the practical solving the problem guys you are going to struggle to keep operational. But without the procedural guys, you are never going to actually find that next step, that better way of doing things. (ME2 - SA)

The ability to link procedural and conceptual understanding is required in the industry. (UL2 - SA)

It was mentioned, however, that there are employment opportunities also for engineers with mainly procedural skills. Interviewees pointed out that engineering problems are usually solved by a partnership between engineers, technologists and technicians; the roles are complementary - you cannot exclude the one or the other.

We have got technologists and technicians to do the procedures and so if there is something done in a standard way it should be done by a technician and not by an engineer. (UL1 - SA)

There is a clear distinction that one should make between an engineer in the true sense of the word and a technologist who would rather be trained to get on with the job and get the answers, but would in most cases not be capable of conceptualising the new design or new approach to a solution for a problem. (UL3 - SA)

We need both kinds of engineers. (ME2 - SA)

In this context, one engineer pointed to a lack of a more conceptual approach in engineering education generally, suggesting that this is a problem not only in mathematics.

I don't blame the mathematics for the type of problems that we have. The whole conceptual understanding is lacking at an engineering level and not a mathematical level. If they get more conceptual exposure at university, they will understand a little bit more about work in the end. But I don't think the fact that mathematics is procedural at this stage is the problem. (PE1 - SA)

In summary, engineers in both countries preferred to employ graduates with welldeveloped conceptual skills, although some engineers saw both types of skills as necessary. South African engineers (in particular) were of the opinion that young engineers who qualify have a lack of conceptual skills. Mention was made that there are employment opportunities also for 'procedural' people but that their task would be more on the level of a 'technologist'.

\subsection{Themes}

Themes defined at the first level of our thematic analysis are presented in Table 1, along with some examples of codes.

During the second step of the analysis, we searched for commonalities and differences across the themes in Table 1, while keeping focus on the overall research question of the study. We named the resulting final two main themes a Conceptual View and a Balanced View (see Figure 1) seeing these opinions expressed by the interviewees as qualitatively distinct and identified across the themes from the first step of the analysis.

According to the conceptual view, a predominantly conceptual approach to mathematics is seen as essential in engineering education as well as in engineering work as it underpins interpretation of problems dealt with, in both the professional and the educational context, and of reality in general, as well of engineering and applications. A conceptual approach is also important for the understanding of real situations and of mathematics itself, and through developing generic thinking abilities. The balanced view, on the other hand, considers both conceptual and procedural skills as essential in engineering education and work through three strands; in linking its conceptual and the procedural aspects, in seeing the procedural aspect as $a$ basis on which the conceptual can be built, and in facilitating the progression from the conceptual problem to its procedural solution. 
Table 1. Themes and examples of codes from the first part of the thematic analysis.

\begin{tabular}{|c|c|c|}
\hline $\begin{array}{l}\text { Interview } \\
\text { Questions }\end{array}$ & $\begin{array}{l}\text { Themes } \\
\text { - Subthemes }\end{array}$ & Examples of Codes \\
\hline \multirow[t]{5}{*}{1} & Adequate preparation & $\begin{array}{l}\text { adequately prepared me for what I needed to do; [no] lacking in } \\
\text { either my conceptual or procedural abilities }\end{array}$ \\
\hline & Good for understanding & it helped me to understand some things \\
\hline & Mainly P (Procedural) & $\begin{array}{l}\text { the maths was very procedural; a lot of procedural mathematics } \\
\text { but no real application }\end{array}$ \\
\hline & Abstract & it was abstract; somewhat away from reality \\
\hline & Not much used & it is very little used; we don't use much of either \\
\hline \multirow[t]{4}{*}{$\mathbf{A}$} & $\begin{array}{l}\text { Low level on } \mathrm{C} \\
\text { (Conceptual) } \\
\text { - Need to teach } C \\
\end{array}$ & $\begin{array}{l}\text { they are struggling conceptually; their conceptual abilities are } \\
\text { very poorly developed } \\
\text { - I need to cover a lot of the required conceptual understanding }\end{array}$ \\
\hline & No link between $\mathrm{C}$ and $\mathrm{P}$ & $\begin{array}{l}\text { [students don't have] that ability to link between conceptual and } \\
\text { procedural; don't make the step from procedural into conceptual }\end{array}$ \\
\hline & Communicate thinking & $\begin{array}{l}\text { students find it difficult to express themselves mathematically; } \\
\text { communicate their thinking }\end{array}$ \\
\hline & Link to applications & they don't understand why they need it \\
\hline \multirow[t]{3}{*}{$2, \mathrm{~B}$} & $\begin{array}{l}\text { C most important } \\
\text { - Understanding } \\
\text { mathematics and } \\
\text { applications } \\
\text { - Mathematics provides a } \\
\text { generic understanding }\end{array}$ & $\begin{array}{l}\text { the conceptual is most important; without a doubt more } \\
\text { conceptual; we don't need the procedural mathematics } \\
\text { - the concepts so they understand what mathematics is; applied } \\
\text { courses in which to understand concepts } \\
\text { - understand how to use their brains and think originally; how } \\
\text { you need to think is what we want from mathematics }\end{array}$ \\
\hline & $\begin{array}{l}\text { Both } \mathrm{C} \text { and } \mathrm{P} \text { are } \\
\text { important }\end{array}$ & $\begin{array}{l}\text { both are important; both procedural and non-procedural design } \\
\text { techniques and thinking }\end{array}$ \\
\hline & $\mathrm{P}$ needed as a basis for $\mathrm{C}$ & $\begin{array}{l}\text { the computational basis for building the conceptual; starting off } \\
\text { with the procedural and then building the conceptual onto that }\end{array}$ \\
\hline \multirow[t]{3}{*}{$3, \mathrm{C}$} & $\begin{array}{l}\text { C most important } \\
\text { - Understanding } \\
\text { - Link to engineering }\end{array}$ & $\begin{array}{l}\text { it is the conceptual today definitely; the conceptual part is the } \\
\text { key; if you don't get the conceptual stuff right it just does not } \\
\text { make sense } \\
\text { - what is important is to understand what it is that you are } \\
\text { really doing } \\
\text { - going more conceptual but also then linking it to engineering }\end{array}$ \\
\hline & $\begin{array}{l}\text { Both } \mathrm{C} \text { and } \mathrm{P} \text { are } \\
\text { important } \\
\text { - Linking } C \text { and } P\end{array}$ & $\begin{array}{l}\text { both are important; it is not either or } \\
\text { - the ability to link the two; because they can't make the link } \\
\text { they don't have an appreciation for the procedural side }\end{array}$ \\
\hline & $\mathrm{P}$ a necessary base for $\mathrm{C}$ & $\begin{array}{l}\text { a procedural base and building a conceptual understanding onto } \\
\text { that; I like the idea of doing it procedurally till you grasp the } \\
\text { concept }\end{array}$ \\
\hline \multirow[t]{2}{*}{$4, D$} & $\begin{array}{l}\text { - Different for engineers } \\
\text { and technologists } \\
\text { - Too low levels of } C\end{array}$ & $\begin{array}{l}\text { have that conceptual to know what you actually do; if you don't } \\
\text { have the conceptual understanding it is quite hard to learn } \\
\text { - we need both kinds of engineers; the conceptual guys are the } \\
\text { bright guys the procedural guys are probably the brilliant guys } \\
\text { there is room for them as well } \\
\text { - they struggle to get to the conceptual side; I do not feel that } \\
\text { the students have the required conceptual skills to be successful } \\
\text { in the workplace } \\
\text { - the whole conceptual understanding is lacking at an } \\
\text { engineering level and not a mathematical level }\end{array}$ \\
\hline & $\begin{array}{l}\text { Both } \mathrm{C} \text { and } \mathrm{P} \text { are } \\
\text { important } \\
\text { - Linking } C \text { and } P\end{array}$ & $\begin{array}{l}\text { if you only have one of those two it feels like it is limping } \\
\text { - the ability to link procedural and conceptual understanding is } \\
\text { required in the industry }\end{array}$ \\
\hline
\end{tabular}


Figure 1. A thematic map including the two main themes, the conceptual view and the balanced view, with subthemes, that were identified in the thematic analysis.

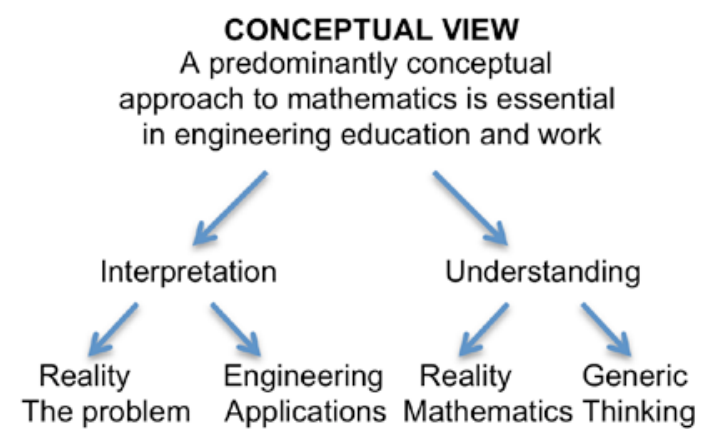

CONCEPTUAL VIEW

A predominantly conceptua A proach to mathematics is essential

The problem Applications Mathematics Thinking

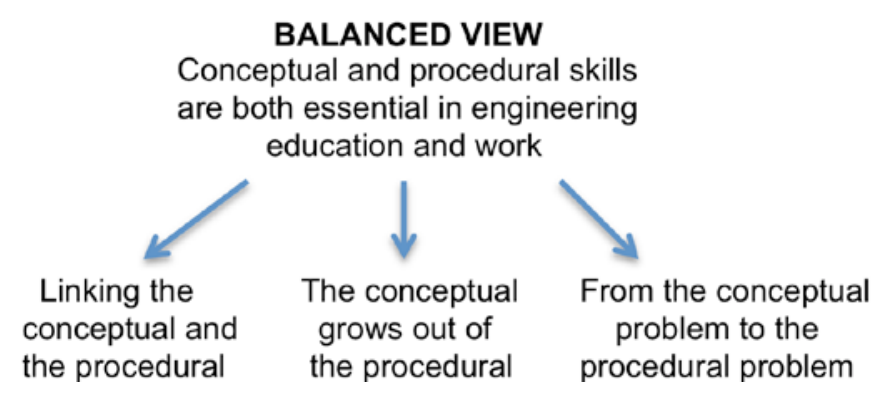

\section{Discussion and conclusion}

The literature review suggests a complex relationship between conceptual and procedural knowledge in mathematics, dynamic in character. This relates to both, how to understand the constructs and the implications of incorporating these analytic categories in the organization of teaching, as well as how engineering students view their relevance for their education. Regarding the needs for engineering work, generally, a variety of aspects of mathematical knowledge are seen as important by different authors, including a good grounding and holistic awareness of the relevance of mathematics as well as computational and communication skills. This is however not sufficient - this knowledge needs to be embedded within an overall engineering judgment and skeptical reverence (Gainsburg 2015). As seen through the data in this study, the views of qualified engineers, as synthesized in Figure 1, on the distinction between the conceptual and the procedural aspects of engagement in mathematical activities, during the education and at work, link to most of these issues.

The interviews support Gainsburg's (2015) view that the epistemic frame surrounding mathematics does not promote an open and critical attitude to application in engineering work. All our interviewees agreed that a conceptual approach to the use of mathematics in engineering work is essential, many of them suggesting that a predominantly conceptual approach is needed (the conceptual view) and valued more than having predominantly procedural skills. Some of the advantages of engineers with good conceptual skills that were mentioned are: conceptual knowledge is easier to apply to other areas; one can more easily switch over to computations; and one can work with greater autonomy. The conceptual approach was here often linked to different aspects of practical engineering work, such as evaluating a model and its computational outcomes and context based problem solving. Such views connect to the conception of skeptical reverence (Gainsburg 2015) as necessary for engineering work (cf. Alpers 2010). Our results support those of Henderson and Broadbridge (2009) as well as those of Vest et al. (1996), in that engineers need a good grounding in mathematics, logical thinking and problem solving. Also the ability to communicate mathematics was emphasised (cf. Goold 2014).

Engineers in both countries, consequently, preferred to employ graduates with welldeveloped conceptual skills in mathematics. Some engineers (in particular South African), however, expressed the opinion that young engineers who qualify have a lack of such skills. University lecturers in both countries were also concerned about the level of conceptual understanding exposed by students in later years of their studies - after having completed the formal mathematics courses. Consequently, as expressed by the practicing engineers in 
particular, the mathematical education of engineers would need to be more conceptually oriented to prepare for the demands at the workplace. However, not only the mathematics courses were to be blamed for students' lack of conceptual skills, as pointed out by one of the practicing engineers who argued for a generally "more conceptual exposure at university".

Even when much computational work now is being done by computers, a balance of conceptual understanding and procedural fluency was still valued by many interviewees (the balanced view), in particular among the Swedish engineers. To understand the "big picture" of a real problem, the "thing in its totality", it is necessary to have knowledge about what is "happening under the surface", that is the computational underpinnings. Thus not only a balance but also the ability to "make the link" between a conceptual and a procedural approach were seen as critical for engineering work. The engineers that were interviewed argued that the conceptual understanding that they are looking for, is the ability to look at a real world problem and to see how it can be translated to a procedural mathematical problem and then also to have an idea of whether the computational results make sense.

Mention was made, by South African engineers, that there are employment opportunities also for people with predominantly procedural skills but that their task would be more on the level of a 'technologist'. In this context, interviewees pointed out that engineering problems are usually solved by a division of labor between engineers, technologists and technicians.

Regarding the organization of the mathematical education of engineers in relation to the conceptual/procedural approaches, almost all engineers interviewed considered a conceptual approach as absolutely essential, but there were two opinions on what order should be followed in the presentation. According to some of the engineers one has to begin with a conceptual problem after which computers can take over. You need the procedural knowledge to be sure about what you are doing. In contrast, some interviewees expressed the opinion that one needs to start with the procedural as a basis and afterwards move over to conceptual applications; one needs a computational basis for "building” a concept.

In our analysis of the interviews, only few differences between the views of the South African and Swedish engineers emerged. ${ }^{4}$ For example, the Swedish engineers had stronger views on the need for keeping a balance between conceptual and procedural skills, whereas the South African engineers felt stronger about the need for a conceptual approach and were more concerned about the absence of a conceptual approach in graduates who are employed. Previous studies (Engelbrecht, Bergsten, and Kågesten 2012; Bergsten, Engelbrecht, and Kågesten 2017) indicate that this difference in opinion may be related to a stronger emphasis on conceptual development in the Swedish engineering education while the South African training has a relatively stronger focus on procedures. It was also observed that while Swedish engineers valued the role of a procedural foundation underpinning the crucial conceptual mathematical understanding (“one must be accurate and can’t be sloppy”), South African engineers felt strongly about the importance of a conceptual basis ("we don't need the procedural mathematics") but also saw a role for people with a strong procedural background - not necessarily then at the level of an engineer but on a somewhat different level of "technologist".

When comparing the three different groups of engineers that were interviewed, our analysis indicated an overall conformity of their views. In both countries, however, university lecturers expressed the strongest concerns about students' lack of conceptual skills and tendencies to only attempt finding some formulas to solve the problems they are facing.

From this interview study based on a qualitative analysis of interview data from a rather small sample of qualified engineers, it is not possible to generalise the findings to a larger

\footnotetext{
${ }^{4}$ Considering that the study was done in purposive and snow ball sampling, these differences could be coincidental.
} 
population. Significance and validity of our results instead rest on the fact that our explorative study was based on a purposive selection of a variety of exemplifying cases from three groups of engineers indeed could identify clear patterns in the data regarding their views on the role of mathematics in engineering education and work (Figure 1). These were also to a high degree common across the contexts, within and between the two countries. While we cannot make claims regarding implications of our study for engineering education, it would nevertheless suggest an overall need to include a substantial amount of conceptually oriented work in the curricula for engineering undergraduate mathematics. However, the study also highlights the complexity of the relation between procedural and conceptual aspects of mathematical work also in the context of engineering practice, and that further empirical research thus will be needed to better understand how to balance conceptual and procedural approaches in mathematics for engineering curriculum design.

Acknowledgements - The authors gratefully acknowledge the financial support from NRF (South Africa) and VR-SIDA (Sweden) for the overarching project for this study. We would also like to thank the reviewers for their valuable comments to previous versions of this article.

\section{References}

Alpers, B. 2010. "Studies on the Mathematical Expertise of Mechanical Engineers.” Journal of Mathematical Modelling and Application 1 (3): 2-17.

Alpers, B. 2013a. “The SEFI Mathematics Working Group’s New Curriculum Framework Document.” In Proceedings from the 41th SEFI Conference, 16-20 September 2013, Leuven, Belgium, edited by L. Froyen. Leuven: SEFI, European Association for Engineering Education.

Alpers, B., ed. 2013b. A Framework for Mathematics Curricula in Engineering Education. A Report of the Mathematics Working Group. Brussels: European Society for Engineering Education (SEFI).

Artigue, M. 2007. "Digital Technologies: A Window on Theoretical Issues in Mathematics Education.” In European Research in Mathematics Education V. Proceedings of CERME6, edited by D. Pitta-Pantazi and G. Philippou, 68-82. Larnaca: University of Cyprus.

Baroody, A. J., Feil, Y., and Johnson, A. R. 2007. “An Alternative Reconceptualization of Procedural and Conceptual Knowledge.” Journal for Research in Mathematics Education 38 (2): 115-131.

Bergsten, C, Engelbrecht, J., and Kågesten, O. 2015. “Conceptual or Procedural Mathematics for Engineering Students - Views of Two Qualified Engineers from Two Countries.” International Journal of Mathematics Education in Science and Technology 46 (7): 979990.

Bergsten, C., Engelbrecht, J., \& Kågesten, O. 2017. “Conceptual and Procedural Approaches to Mathematics in the Engineering Curriculum - A Comparison between Conceptions and Performance of Junior and Senior Engineering Students in Two Countries.” Eurasia Journal of Mathematics, Science and Technology Education 33 (3): 533-553.

Braun, V., and Clarke, V. 2006. “Using Thematic Analysis in Psychology.” Qualitative Research in Psychology 3 (2): 77-101. 
Brown, S., Seidelmann, A., and Zimmermann, G. 2006. "In the Trenches: Three Teachers' Perspectives on Moving Beyond the Math Wars.” Resource Document. Mathematically sane. Retrieved from http://omca-outreach.wikispaces.com/

Bryman, A. 2004. Social Research Methods (2. ed.). Oxford: Oxford University Press.

Cardella, M. E. 2008. "Which Mathematics Should We Teach Engineering Students? An Empirically Grounded Case for a Broad Notion of Mathematical Thinking.” Teaching Mathematics and its Applications 27 (3): 150-159.

Chappell, K. K., and Killpatrick, K. 2003. "Effects of Concept-Based Instruction on Students' Conceptual Understanding and Procedural Knowledge of Calculus.” Primus 13 (1): 17-37.

Chundi, A. 2013. “8 Most Important Skills Required for an Engineer.” Retrieved from http://www.skyfilabs.com/blog/8-most-important-skills-required-for-an-engineer

Crawley, E. F. 2001. The CDIO Syllabus: A Statement of Goals for Undergraduate Engineering Education. Department of Aeronautics and Astronautics, Massachusetts Institute of Technology. Retrieved 25 March 2016 from http://www.cdio.org/files/CDIO_Syllabus_Report.pdf

Engelbrecht, J., Bergsten, C, and Kågesten, O. 2009. "Undergraduate Students’ Preference for Procedural to Conceptual Solutions to Mathematical Problems.” International Journal of Mathematics Education in Science and Technology 40 (7): 927-940.

Engelbrecht, J., Bergsten, C, and Kågesten, O. 2012. “Conceptual and Procedural Approaches to Mathematics in the Engineering Curriculum: Student Conceptions and Performance.” Journal of Engineering Education 101 (1): 138-162.

Flegg, J., Mallet, D., and Lupton, M. 2012. “Students’ Perceptions of the Relevance of Mathematics in Engineering.” International Journal of Mathematical Education in Science and Technology 43 (6): 717-732.

Gainsburg, J. 2015. “Engineering Students’ Epistemological Views on Mathematical Methods in Engineering.” Journal of Engineering Education 104 (2): 139-166.

Goold, E. 2014. "Putting Mathematics 'into a form that a non-engineer will understand'." SEFI 2014 Annual Conference: Educating Engineers for Global Competitiveness. Birmingham, UK.

Grimson, J. 2002. "Re-Engineering the Curriculum for the 21st Century.” European Journal of Engineering Education 27 (1): 31-37.

Groth, R. E., and Bergner, J. A. 2006. "Preservice Elementary Teachers' Conceptual and Procedural Knowledge of Mean, Median, and Mode.” Mathematical Thinking and Learning 8 (1): 37-63.

Håstad, M. 1968. “Mathematics and Engineers.” Educational Studies in Mathematics 1: 9397.

Henderson, S., and Broadbridge, P. 2009. “Engineering Mathematics Education in Australia.” MSOR Connections 9 (1): 12-17. Retrieved 25 March 2016 from https://www.heacademy.ac.uk/engineering-mathematics-education-australia

Hiebert, J., and Lefevre, P. 1986. "Procedural and Conceptual Knowledge in Mathematics: An Introductory Analysis.” In Conceptual and procedural knowledge: The case of mathematics, edited by J. Hiebert, 1-27. Hillsdale, NJ: Erlbaum. 
Hiebert, J., and Carpenter, T. 1992. “Learning and Teaching with Understanding.” In Handbook of research on mathematics teaching and learning, edited by D. Grouws, 65-97. New York: Macmillan Publishing Company.

Houston, K., Mather, G., Wood, L. N., Petocz, P., Reid, A., Harding, A., Engelbrecht, J., and Smith, G. 2010. "Is there Life after Modelling? Student Conceptions of Mathematics.” Mathematics Education Research Journal 22 (2): 69-80.

Hult, H., Dahlgren, M. A., Dahlgren, L. O, and Hård af Segerstad, H. 2003. Freshmen’s and Seniors' Thoughts about Education, Professional Identity, and Work. Australian Association for Research in Education Conference, 2003. Retrieved 25 March 2016 from http://www.aare.edu.au/data/publications/2003/dah03725.pdf

Kent, P., and Noss, R. (2003). Mathematics in the University Education of Engineers. Ove Arup Foundation Report. London: Ove Arup Foundation. Retrieved 25 March 2016 from http://www.lkl.ac.uk/research/REMIT/Kent-Noss-report-Engineering-Maths.pdf

Kieran, C. 2013. "The False Dichotomy in Mathematics Education between Conceptual Understanding and Procedural Skills: an Example from Algebra.” In Vital Directions for Mathematics Education Research, edited by K. R. Leatham, 153-171. New York, NY: Springer.

Klingbeil, N. W., Mercer, R. E., Rattan, K. S., Raymer, M. L., and Reynolds, D. B. 2005. “The WSU Model for Engineering Mathematics Education.” In Proceedings of the 2005 American Society for Engineering Education Annual Conference \& Exposition. Retrieved 17 March 2015 from http://corescholar.libraries.wright.edu/cgi/viewcontent.cgi?article=2300\&context=knoesis

Lappalainen, P. 2009. “Communication as Part of the Engineering Skills Set.” European Journal of Engineering Education 34 (2): 123-129.

Markes, I. 2006. “A Review of Literature on Employability Skill Needs in Engineering.” European Journal of Engineering Education 31 (6): 637-650.

Nair, C. S., Patil, A., and P. Mertova, P. 2009. “Re-engineering Graduate Skills.” European Journal of Engineering Education 34 (2): 131-139.

Nguyen, D. Q. 1998. “The Essential Skills and Attributes of an Engineer: A Comparative Study of Academics, Industry Personnel and Engineering Students.” Global Journal of Engineering Education 2 (1): 65-79.

Peled, I., and Zaslavski, O. 2008. "Beyond Local Conceptual Connections: Meta-Knowledge about Procedures.” Learning Mathematics 28 (3): 28-35.

Perdigones, A., Gallego, E., García, N., Fernández, P., Pérez-Mártin, E., and Del Cerro, J. 2014. "Physics and Mathematics in the Engineering Curriculum: Correlation with Applied Subjects.” International Journal of Engineering Education 30 (6A): 1509-1521.

Petocz, P., Reid, A., Wood, L. N., Smith, G. H., Mather, G., Harding, A., Engelbrecht, J., Houston, K., Hillel, J., and Perrett, G. 2007. "Undergraduate Students' Conceptions of Mathematics: An International Study.” International Journal of Science and Mathematics Education 5 (3): 439-459.

Radu, M. 2002. "Basic Skills versus Conceptual Understanding in Mathematics Education: The Case of Fractions and Division. A reply to Hung-Hsi Wu.” ZDM 34 (3): 93-95. 
Rittle-Johnson, B., and Schneider, M. 2015. “Developing Conceptual and Procedural Knowledge of Mathematics. In Oxford Handbook of Numerical Cognition, edited by R. Cohen Kadosh and A. Dowker, 1118-1134. Oxford, UK: Oxford University Press.

Rittle-Johnson, B., Siegler, R. S., and Alibali, M. W. 2001. "Developing Conceptual Understanding and Procedural Skill in Mathematics: An Iterative Process.” Journal of Educational Psychology 93: 346-362.

Star, J. R. 2005. “Reconceptualizing Procedural Knowledge.” Journal for Research in Mathematics Education 36 (5): 404-411.

Vest, D., Long, M., and Anderson, T. 1996. “Electrical Engineers’ Perceptions of Communication Training and their Recommendations for Curricular Change: Results of a National Survey.” IEEE Transactions on Professional Communication 39 (1): 38-42.

Winkelman, P. 2009. "Perceptions of Mathematics in Engineering.” European Journal of Engineering Education 34 (4): 305-316.

Wood, L. N. 2010. “Graduate capabilities: putting mathematics into context.” International Journal of Mathematical Education in Science and Technology 41 (2): 189-198.

Wood, L. N., Mather, G., Petocz, P., Reid, A., Engelbrecht, J., Harding, A., Houston, K., Smith, G., and Perret, G. 2012. "University Students' Views of the Role of Mathematics in their Future.” International Journal of Science and Mathematics Education 10 (1): 99-119.

Wood, L. N., and Solomonides, I. 2008. “Different Disciplines, Different Transitions.” Mathematics Education Research Journal 20 (2): 117-134.

Wu, H. 1999. "Basic Skills versus Conceptual Understanding: A Bogus Dichotomy in Mathematics Education.” American Educator, Fall 1999. Resource document. AFT, A Union of Professionals. Retrieved on 10 March 2015 from www.aft.org/pdfs/americaneducator/fall1999/wu.pdf 